\title{
Simple changes can improve conduct of end-of- life care in the intensive care unit
}

\author{
[Des changements simples peuvent améliorer les soins aux mourants à l'unité des \\ soins intensifs]
}

Richard I. Hall MD FRCPC FCCP, ${ }^{*}$ Graeme M. Rocker MHSc DM FRCP FRCPC, $†$ Dawnelda Murray Rn $\ddagger$

Purpose: To describe changes to the conduct of withdrawal of life support (WOLS) in two teaching hospital tertiary care medical surgical intensive care units (ICUs) in a single centre over two distinct time periods.

Methods: We used a retrospective chart review with a before and after comparison. We assessed aspects of end-of-life care for ICU patients dying after a WOLS before and after we introduced instruments to clarify do not resuscitate (DNR) orders and to standardize the WOLS process, sought family input into the conduct of end-of-life care, and modified physicians' orders regarding use of analgesia and sedation.

Results: One hundred thirty-eight patients died following life support withdrawal in the ICUs between July 1996 and June 1997 (PRE) and 168 patients died after a WOLS between May 1998 and April 1999 (POST). Time from ICU admission to WOLS (mean \pm SD) was shorter in the POST period ( $191 \pm 260 \mathrm{hr}$ PRE vs $135 \pm$ $205 \mathrm{hr}$ POST, $P=0.05)$. Fewer patients in the POST group received cardiopulmonary resuscitation in the 12-hr interval prior to death (PRE $=7$; POST $=0: P<0.05)$. Fewer comfort medications were used (PRE: $1.7 \pm 1.0$ vs POST: $1.4 \pm 1.0 ; P<0.05)$. Median cumulative dose of diazepam (PRE: 20.0 vs POST: 10.0 mg; $P<0.05)$ decreased. Documented involvement of physicians in WOLS discussions was unchanged but increased for pastoral care (PRE: 10/I38 vs POST: $120 / 168$ cases; $P<0.05)$. The majority of nurses $(80 \%)$ felt that the DNR and WOLS checklists led to improved process around WOLS.

Conclusion: Simple changes to the process of WOLS can improve conduct of end-of-life care in the ICU.
Objectif : Décrire les changements apportés au retrait du maintien des fonctions vitales (RMFV) dans deux unités de soins intensifs (USI) médicaux et chirurgicaux d'un centre hospitalier universitaire de soins tertiaires au cours de deux périodes distinctes.

Méthode : Nous avons utilisé une revue rétrospective des dossiers et réalisé une comparaison du type avant-après. Nous avons évalué les différents aspects des soins aux mourants de l'USI, décédés après le $R M F V$, avant et après l'introduction d'instruments clarifiant l'ordonnance de ne pas réanimer (PDR) et normalisant le processus de RMFV. Nous avons recueilli les suggestions de la famille sur les soins aux mourants et modifié les ordonnances des médecins sur l'analgésie et la sédation.

Résultats : Cent trente-huit patients sont décédés après le RMFV dans les USI entre juillet 1996 et juin 1997 (PRE) et 168 après un RMFV entre mai 1998 et avril 1999 (POST). L'intervalle entre l'admission à I'USI et le RMFV (moyenne \pm écart type) a été plus court dans la période POST ( $191 \pm 260$ h PRE vs $135 \pm 205$ h POST, $P=$ 0,05). Moins de patients du groupe POST ont reçu une réanimation cardiopulmonaire dans les $12 \mathrm{~h}$ précédant la mort (PRE $=7$; POST $=0: P<0,05)$. Moins de médicaments de confort ont été utilisés (PRE : $1,7 \pm 1,0$ vs POST : $1,4 \pm 1,0 ; P<0,05$ ). La dose cumulative moyenne de diazépam (PRE : 20,0 vs POST: 10,0 mg ; $P<$ $0,05)$ a diminué. La participation des médecins aux discussions sur le RMFV n'a pas changé mais les interventions du service de pastorale ont augmenté (PRE : 10/138 vs POST : $120 / 168$ cas ; $P<0,05$ ). La majorité des infirmières (80\%) croyaient que les ordonnances modifiées de PDR et de RMFV ont permis d'améliorer le traitement entourant le RMFV.

Conclusion : Des changements simples au processus de RMFV peuvent améliorer les soins aux mourants dans une USI.

From the Departments of Anesthesia, ${ }^{*}$ and Medicine, $†$ Dalhousie University, and the Intensive Care Services, $\ddagger$ Queen Elizabeth II Health Sciences Centre, Halifax, Nova Scotia, Canada.

Address correspondence to: Dr. Graeme Rocker, Critical Care Program, Queen Elizabeth II Health Sciences Centre, 1796 Summer Street, Room 4457 HI, Halifax, Nova Scotia B3H 3A7, Canada. Phone: 902-473-6611; Fax: 902-473-6202; E-mail: gmrocker@dal.ca Institution at which work was performed: Queen Elizabeth II Health Sciences Centre.

Manuscript assessed August 19, 2003.

1 st revision accepted November 21, 2003.

Final revision accepted March 24, 2004. 


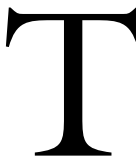

HE landmark study to understand prognoses and preferences for outcomes and risks of treatment (SUPPORT) demonstrated that many patients at the end-of-life receive care incongruent with their wishes. ${ }^{1}$ Subsequently there have been many calls for better defined goals for, and better care of, dying patients in the intensive care units (ICUs). ${ }^{2-7}$

Improvements to care in the ICU could take many forms: attention to communication strategies, better understanding of cultural issues, use of ethical committees in difficult cases or process issues within the ICU to improve consistency in care delivery. Regarding consistency, we recently reported tenfold variations in prescribed doses of morphine during the last $12 \mathrm{hr}$ of life in dying ICU patients. ${ }^{8}$ Others have reported variability in other aspects of end-of-life care e.g., the frequency; ${ }^{9-11}$ the manner; ${ }^{7,12-14}$ and the biases that individual physicians bring to the process of life support withdrawal. ${ }^{15-19}$ Practice variation does not best serve the needs of patients or those responsible for managing them during the dying process. Understanding practice variation and addressing concerns over suboptimal process issues within an ICU are bases for introducing change.

The purpose of this report is to describe changes to the conduct of withdrawal of life support (WOLS) in two teaching hospital tertiary care medical surgical ICUs in a single centre.

\section{Materials and methods}

We compared aspects of end-of-life care in two phases in the two closed, academic adult medical/surgical ICUs ( 24 beds in total) at the Queen Elizabeth II Health Sciences Centre (QEII HSC, 826 beds), the only acute care medical centre for Halifax, Nova Scotia, (catchment population 250,000 ). It is a tertiary/quaternary care referral centre for the Atlantic Canadian provinces.

\section{Phase I (PRE)}

Following legal action against one of our colleagues after a WOLS [a first degree murder charge (later dismissed)], ${ }^{20,21}$ we reviewed care of all patients dying in the ICU from July 1996 to June 1997. The results of this review are reported in detail elsewhere. ${ }^{8}$ In brief, we described the use of technological support, variability in physician documentation of end-of-life discussions, and use of medication in the last $12 \mathrm{hr}$ of life in 174 dying patients of whom 36 died despite active support and 138 after life support was forgone. During this time period, ten intensivists cared for patients in the ICU, providing $24 \mathrm{hr}$ coverage and rotating on a weekly basis.

\section{Interventions}

After phase I we discussed the practice review ${ }^{8}$ with ICU nurses and physicians at all levels (usually in small group focus sessions) and ensured that all members of staff had the opportunity to attend sessions to discuss end-of-life care. Three initiatives were then implemented: 1) concerns regarding end-of-life care were solicited from the ICU nursing staff and from ten families of patients who died in the ICU, by requesting written feedback. To address issues raised, instruments were developed and refined (see below under instrument development and also Appendices A and B, available as Additional Material at www.cja-jca.org); 2) nursing progress note entries were altered to reflect more complete documentation of dyspnea, pain, agitation and their management; 3 ) use of open-ended orders (i.e., no fixed upper limit to amount of drug which could be administered) was proscribed. These initiatives were implemented between July 1997 and December 1997.

\section{Contacting families and instrument development}

To elicit concerns of families before any intervention, one of us (D.M.) conducted telephone interviews with next-of-kin of ten patients who had died in the ICU, at least six months after death. Issues identified during a semi-structured interview included: insufficient involvement of members from the religious community; perceptions of pain and discomfort during the dying process and communication between staff physicians and others involved in the care of the ICU patient, particularly as WOLS was discussed and implemented. To address these issues we included specific items and procedures in the WOLS instrument (Appendix A). Feedback from another ten patients who survived the ICU and family members of 20 patients who died enabled us to refine our interventions and instruments.

\section{Feedback from nurses}

Nurses wanted more involvement in discussions with families about WOLS, appropriate documentation, and timely discontinuation of technical interventions (e.g., dialysis) when a decision was made to withdraw life support. A do not resuscitate (DNR) order instrument (Appendix B) reflected the need for timely discussion and clarification of intentions of a DNR order. Nurses also expressed concern over the numbers and amounts of drugs for comfort before physician notification was required. Moreover, the results of an internal scenario-based survey received from eight of eight intensivists and from 75 of 144 nurses indicated major differences in prescribing habits for physicians and 
nursing interpretation of physicians' open-ended orders. This finding led to a policy of no 'open-ended' physician orders. We also modified the nursing policy and progress notes to require documentation and allow adjustment of comfort medication based on patient-specific targeted sedation and analgesic levels.

\section{Educational development}

A core group of staff nurses from the participating ICUs met with other staff to discuss issues surrounding improvement of end-of-life care. The investigators met monthly to develop and refine the instruments, and one of us (D.M.) liased each month with the core group of staff nurses to make alterations to nursing notes, and provide education on symptom management including medication during the WOLS process.

\section{Phase II (POST)}

The medical records of patients dying in the ICU between May 1998 and April 1999 were reviewed and data were abstracted.

\section{Definitions}

We used the following definitions: Forgoing (withholding/withdrawing) life support - removal or no further addition or escalation of major life support modalities including inotropes, mechanical ventilation, dialysis etc., with the recognition that this would likely result in the patient's death from the underlying medical condition. We did not distinguish between withholding or WOLS. Comfort measures - the administration of drugs such as narcotics and sedatives to prevent symptomatic discomfort occurring during the dying process.

\section{Data abstraction}

Information was collected by two reviewers (R.H. and D.M.) to maintain consistency. Any discrepancies were adjudicated and resolved by consensus. We recorded: patient age; gender; reason for ICU admission; whether admitted from a medical or surgical service; date of hospital admission; date of ICU admission; ICU admission diagnosis; admission APACHE II score; ${ }^{22}$ date and time of death; cause of death; hospital length of stay; ICU length of stay; attending intensivist at the time of death; date and time at which a decision was made to forgo life support; mechanical ventilatory status at time of death; whether life support was forgone and, if so, date and time; time from forgoing of life support to death. Treatments received in the final $12 \mathrm{br}$ of life refers to: mechanical ventilation; dialysis; nutritional support; changes to the inspired oxygen fraction $\left(\mathrm{FIO}_{2}\right)$ and all medication use. Life support related discussions refers to: docu-
TABLE I Demographic variables, ICU characteristics and treatments forgone in the two study periods

\begin{tabular}{|c|c|c|c|}
\hline Variable & $\begin{array}{l}\text { PRE } \\
(n=138)\end{array}$ & $\begin{array}{l}\text { POST } \\
(n=168)\end{array}$ & P value \\
\hline Gender $(\mathrm{F} / \mathrm{M})$ & $69 / 69$ & $70 / 98$ & 0.14 \\
\hline Age (yr) & $65 \pm 16$ & $60 \pm 18$ & 0.01 \\
\hline Admission APACHE II score & $25 \pm 9$ & $23 \pm 7$ & 0.08 \\
\hline Medical patient $n,(\%)$ & $67(49)$ & $86(51)$ & 0.65 \\
\hline \multicolumn{4}{|l|}{ Mechanical ventilation } \\
\hline at death $n,(\%)$ & $82(59)$ & $100(60)$ & 1.0 \\
\hline duration (hr) & $\begin{array}{l}162 \pm 223 \\
(n=119)^{*}\end{array}$ & $124 \pm 191$ & 0.14 \\
\hline $\begin{array}{l}\text { Time from ICU admission } \\
\text { to WOLS (hr) }\end{array}$ & $\begin{array}{l}191 \pm 260 \\
(n=107)^{*}\end{array}$ & $135 \pm 205$ & 0.05 \\
\hline Time to death after WOLS (hr) & $\begin{array}{l}4.3 \pm 11.3 \\
(n=105)^{*}\end{array}$ & $6.1 \pm 9.3$ & 0.72 \\
\hline \multicolumn{4}{|l|}{ Length of stay } \\
\hline ICU (days) & $7.0 \pm 9.0$ & $5.7 \pm 8.2$ & 0.18 \\
\hline hospital (days) & $16.4 \pm 22.2$ & $10.5 \pm 14.1$ & 0.005 \\
\hline
\end{tabular}

ICU $=$ intensive care unit; PRE = prior to introduction of end-oflife care initiatives; POST $=$ following introduction of end-of-life care initiatives; WOLS = withrawal of life support. *For whom documentation was adequate. Values are expressed as mean \pm SD unless otherwise indicated.

mented plans to forgo life support by staff intensivists and/or other physicians anywhere in the medical record and/or written evidence of involvement of pastoral care services for family support.

\section{Data analysis}

For demographic variables, categorical data were analyzed using Chi square or Fisher's exact test, and continuous data were analyzed by $t$ test or ANOVA. Differences in hourly drug dose over time were analyzed by Kruskal-Wallis test for repeated measurements. We used the Mann Whitney $U$ test to determine differences in median cumulative dose of medication. Differences between groups for use of life support measures and incidence of documentation of discussions were compared using a Chi square analysis. Differences were accepted as statistically significant when $P<0.05$ (Systat ${ }^{\circledR}$ v 10.0 statistical software (SPSS Inc., Chicago, IL, USA). Unless otherwise indicated, data results are expressed as mean $( \pm$ SD) or as median (range).

\section{Results}

\section{Demographics}

During the POST period, there were 1,660 ICU admissions and 209 deaths (13\%). Life support was forgone for 168 patients $(80 \%)$. These figures are similar to those in the PRE period, with a $13 \%$ mortality 
TABLE II Treatments forgone

\begin{tabular}{|c|c|c|c|c|c|}
\hline \multirow[t]{2}{*}{ Treatment } & \multicolumn{2}{|c|}{$\operatorname{PRE}(n=138)$} & \multicolumn{2}{|c|}{$\operatorname{POST}(n=168)$} & \multirow{2}{*}{ P valu } \\
\hline & $\gamma_{e s}$ * & $\mathrm{No}^{* *}$ & $\gamma_{e s} *$ & $\mathrm{No}^{* *}$ & \\
\hline Inotropic support $(n)$ & 117 & 21 & 138 & 30 & 0.54 \\
\hline Nutrition $(n)$ & 116 & 22 & 153 & 15 & 0.06 \\
\hline $\begin{array}{l}\text { Final } \mathrm{FIO}_{2} \\
{[0.21-1.0(95 \% \mathrm{CI})]}\end{array}$ & \multicolumn{4}{|c|}{$0.36(0.29-0.40) 0.41(0.33-0.44)$} & 0.14 \\
\hline
\end{tabular}

$\mathrm{PRE}=$ prior to introduction of end-of-life care initiatives; POST $=$ following introduction of end-of-life initiatives; $\mathrm{CI}=$ confidence interval. ${ }^{*}$ Yes $=$ treatment forgone $;{ }^{*}$ No $=$ treatment continued until death occurred; ${ }^{* *}$ For whom data was available.

TABLE III Twelve hour cumulative dose of comfort medications

\begin{tabular}{llll}
\hline Drug & PRE $^{*}$ & POST $^{* *}$ & P value \\
\hline Morphine (mg) & $n=108$ & $n=102$ & \\
& $32(1-698)$ & $22(1-2600)$ & 0.15 \\
Diazepam (mg) & $n=45$ & $n=26$ & \\
& $20(2.5-155)$ & $10(2.5-62)$ & 0.01 \\
Midazolam (mg) & $n=45$ & $n=44$ & \\
& $10(0.5-593)$ & $7.5(1-168)$ & 0.62 \\
Lorazepam (mg) & $n=8$ & $n=18$ & \\
& $5.5(1-60)$ & $7.0(0-137)$ & 0.78 \\
Propofol (mg) & $\mathrm{n}=14$ & $n=28$ & \\
& $1672(112-61308)$ & $935(10-4300)$ & 0.14 \\
\hline
\end{tabular}

* $\mathrm{PRE}=$ prior to introduction of end-of-life care initiatives; $*$ *POST $=$ following introduction of end-of-life care initiatives. Values are expressed as median (range). Tests for normality of the data indicated the data were not normally distributed.

and an incidence of forgoing life support of $79 \% .{ }^{8} \mathrm{We}$ describe demographic data and the ICU course for the patients in Table I. Patients in the POST group were younger and time from ICU admission to WOLS was shorter in the POST period. Once life support was forgone, time to death was similar in both groups. Hospital length of stay (but not ICU length of stay) was longer PRE vs POST. In the PRE group, a greater proportion of patients died from pneumonia (21/138 vs $12 / 168 ; P<0.05)$, intra-abdominal sepsis $(22 / 138$ vs $7 / 168 ; P<0.05)$ and fewer died from trauma $(0 / 138$ vs $12 / 168 ; P<0.05)$ or neurological insult $(17 / 138$ vs $50 / 168 ; P<0.05)$. Otherwise all other causes of death were similar in the two phases (data not shown).

\section{Treatments forgone}

There was a trend toward a reduction in the provision of nutritional support in the POST group (Table II). More patients in the PRE group had received cardiopulmonary resuscitation (CPR) $(\mathrm{PRE}=7$ vs $\mathrm{POST}$ $=0 ; P<0.05)$ in the 12 -hr interval prior to death. The number of patients receiving dialysis in this 12 -hr peri- od was similar $(\mathrm{PRE}=2$ vs $\mathrm{POST}=4)$. No patient in either group received CPR or dialysis once the decision to forgo life support was made.

\section{Use of comfort medication}

We noted a reduction in the number of comfort medications administered per patient $(1.7 \pm 1.0$ vs $1.4 \pm$ 1.0; $P=0.005)$. We noted a significant reduction in the cumulative median dose of diazepam administered for comfort in the POST group (Table III), although morphine dosing was unchanged.

\section{Documentation of the life support withdrawal process}

Documentation by physicians of life support related discussions was similar in the PRE (120/138) vs POST (148/168) periods. Documented involvement of pastoral care in the support of families of dying patients increased (ten cases noted PRE ps 120 cases POST; $P<0.05)$. When combined, documentation of WOLS discussions by some members of the health care team occurred in $135 / 138$ cases PRE vs $161 / 168$ cases POST.

\section{Staff satisfaction}

A majority (65\%) of 45 staff nurses responding to an internal utilization survey of our checklists were comfortable using them and felt that an improvement had occurred in the process of life support withdrawal. In particular, $~ 80 \%$ of nurses felt the DNR checklist had resulted in much clearer physician orders and the WOLS checklist in a more consistent process. Most nurses felt that the development of checklists and objective scoring systems (for pain, sedation and dyspnea) had improved patient care at the end-of-life.

\section{Discussion}

In this single institution review of end-of-life care in an ICU, implementation of some simple initiatives improved our process of WOLS. These initiatives, based on a practice review and feedback from families and staff, included an aide memoire (Appendix A) to be used during the WOLS process and a checklist to clarify levels of care (Appendix B). We focused on earlier discussions of goals of care. This resulted in less frequent CPR prior to decisions to forgo life support, a reduction in the time from admission to the ICU to the institution of WOLS when death was inevitable, and increased attention to spiritual needs as life approached its end.

We noted a reduction in the number of comfort medications employed at the end-of-life suggesting less variability in drug prescriptions. Establishing upper limits for drugs at a specified time required 
more dialogue between the bedside nurse and attending physician and required the attending physician to more closely supervise the dying process. We accept that earlier adverse publicity surrounding legal charges against a colleague may have resulted in more conservative prescriptions for some comfort medications but similar usage of morphine and comparison of individual practices suggested that this was not the case. In specific circumstances physicians used high doses of comfort medications when required as reflected in the range of doses for medications in Table III. Moreover, some physicians in the POST group had not been part of the cohort of intensivists scrutinized during the legal proceedings. We also recognize that the higher proportion of patients with identified neurological comorbidities may have limited the doses of medications prescribed. The increased proportion of patients with neurological co-morbidities likely reflects the incorporation of neurosurgical patients into the case mix occurring primarily in the POST period as a result of regional health care reorganization rather than any change in other demography.

Documentation of discussions surrounding end-oflife issues was high PRE and POST with little room for improvement. We firmly believe that failure of clear documentation of such discussions is as difficult to justify at the end-of-life as it is when the initial focus is curative.

Strengths of our practice review include the fact that participating physicians, including the authors, were unaware that any comparison of practice would be made at the time that these events occurred. The retrospective nature of this study avoided any inherent biases in this regard. The similar admission APACHE II score and the similar rate with which life support was forgone suggest the two groups, as defined, were suitable for comparison although we accept there was an increased incidence of central nervous system related co-morbidities, a reduced incidence of death from pneumonia and sepsis in the PRE period, and more trauma patients in the POST period. We sought to characterize and improve processes following the decision to forgo life support. We established a baseline by examining a retrospective review of a cohort of patients dying prior to introduction of our changes. We surveyed our staff and the families of patients dying in the ICU to determine any perceived deficiencies in the provision of end-of-life care, including the process of forgoing of life support, and introduced initiatives to address these issues. Finally, after an appropriate time to allow the 'novelty' of the changes to wear off (July 1997 to April 1998), we determined whether we had made any noteworthy changes in our end-of-life care.
Our results suggest some improvements have occurred. There is robust evidence that multi-method initiatives such as this can change behaviour. ${ }^{23}$ We used five effective behaviour change strategies: 1) audit; 2) feedback about the audit results; 3 ) reminders to all ICU clinicians (e.g., the WOLS checklist); 4) use of protocols; 5) involvement of the investigators as committed local opinion leaders.

Our practice review has several important limitations. We recognize the deficiencies of a retrospective review and accept that a randomized controlled trial of our interventions would have been preferable. Our study was conducted in one institution and results might not be generalizable to other centres, but the improvement initiatives were simple and, we believe, could be repeated elsewhere. We recognize that the number of families surveyed was small and this limits validity of any statistical analysis of their responses. In addition we did not conduct a PRE and POST analysis of staff or family satisfaction. The degree to which ongoing legal action influenced behaviour in the early portion of the POST period should not be discounted. However, we believe that this factor likely diminished with time. We were unable to assess compliance with the instruments developed but the adoption of the instruments both in our institution and by others [see under ICU policies (3.ICU order forms) at www.promotingexcellence.org/navigate/critical_care _bib.html] is, we believe, an indication of positive changes in approach to end-of-life care in ICUs.

In summary, quality improvement initiatives similar to ours have the potential to positively address concerns expressed by patients, families and health care teams in the ICU. The identification of areas of concern requires a commitment to effective communication both within and between ICU health care teams and patients and families in the ICU.

\section{Acknowledgements}

We thank our patients and families, the ICU nursing and medical staff, and the Institute for Health Care Improvement for providing us with the inspiration to try to improve end-of-life care in our ICUs.

\section{References}

1 Anonymous. A controlled trial to improve care for seriously ill hospitalized patients. The study to understand prognoses and preferences for outcomes and risks of treatments (SUPPORT). The SUPPORT Principal Investigators. JAMA 1995; 274: 1591-8.

2 Roy DJ. The times and places of palliative care (Editorial). J Palliat Care 2000; 16(Suppl): S3-4.

3 Rocker GM, Shemie SD, Lacroix J. End-of-life issues in 
the ICU: a need for acute palliative care? (Editorial). J Palliat Care 2000; 16(Suppl): S5-6.

4 Nelson JE, Danis $M$. End-of-life care in the intensive care unit: where are we now? Crit Care Med 2001; 29: N2-9.

5 Danis M, Federman D, Fins JJ, et al. Incorporating palliative care into critical care education: principles, challenges, and opportunities. Crit Care Med 1999; 27: 2005-13.

6 Levy MM. End-of-life care in the intensive care unit: can we do better? Crit Care Med 2001; 29: N56-61.

7 Faber-Langendoen K, Lanken PN. Dying patients in the intensive care unit: forgoing treatment, maintaining care. Ann Intern Med 2000; 133: 886-93.

8 Hall RI, Rocker GM. End-of-life care in the ICU. Treatments provided when life support was or was not withdrawn. Chest 2000; 118: 1424-30.

9 Prendergast TJ, Luce JM. Increasing incidence of withholding and withdrawal of life support from the critically ill. Am J Respir Crit Care Med 1997; 155: 15-20.

10 Prendergast TJ, Claessens MT, Luce JM. A national survey of end-of-life care for critically ill patients. Am J Respir Crit Care Med 1998; 158: 1163-7.

11 Keenan SP, Busche KD, Chen LM, Esmail R, Inman KJ, Sibbald WJ. Withdrawal and withholding of life support in the intensive care unit. A comparison of teaching and community hospitals. The Southwestern Ontario Critical Care Research Network. Crit Care Med 1998; 26: 245-51.

12 Asch DA, Hansen-Flaschen J, Lanken PN. Decisions to limit or continue life-sustaining treatment by critical care physicians in the United States: conflicts between physicians' practices and patients' wishes. Am J Respir Crit Care Med 1995; 151: 288-92.

13 Faber-Langendoen $K$. The clinical management of dying patients receiving mechanical ventilation. A survey of physician practice. Chest 1994; 106: 880-8.

14 Cook DJ, Giacomini M, Johnson N, Willms D. Life support in the intensive care unit: a qualitative investigation of technological purposes. Canadian Critical Care Trials Group. CMAJ 1999; 161: 1109-13.

15 Kollef $M H$. Private attending physician status and the withdrawal of life-sustaining interventions in a medical intensive care unit population. Crit Care Med 1996; 24: 968-75.

16 Asch DA, Faber-Langendoen K, Shea JA, Christakis $N A$. The sequence of withdrawing life-sustaining treatment from patients. Am J Med 1999; 107: 153-6.

17 Asch DA, Christakis NA. Why do physicians prefer to withdraw some forms of life support over others? Intrinsic attributes of life-sustaining treatments are associated with physicians' preferences. Med Care 1996; 34: 103-11.
18 Christakis NA, Asch DA. Biases in how physicians choose to withdraw life support. Lancet 1993; 342: 642-6.

19 Christakis NA, Asch DA. Medical specialists prefer to withdraw familiar technologies when discontinuing life support. J Gen Intern Med 1995; 10: 491-4.

20 Robb N. Death in a Halifax hospital: a murder case highlights a profession's divisions. CMAJ 1997; 157: 757-62.

21 Robb $N$. The Morrison ruling: the case may be closed but the issues it raised are not. CMAJ 1998; 158: $1071-2$.

22 Knaus WA, Draper EA, Wagner DP, Zimmerman JE. APACHE II: a severity of disease classification system. Crit Care Med 1985; 13: 818-29.

23 Grimshaw JM, Shirran L, Thomas R, et al. Changing provider behavior. An overview of systematic reviews of interventions. Med Care 2001; 39(Suppl 2): II-2-II-45. 